\title{
Playing the triangle: Cosmopolitanism, Cultural Capital and Social Capital as intersecting scholarly discourses about social inclusion and marginalisation in Australian public policy debates ${ }^{1}$
}

\author{
Andrew Jakubowicz \\ University of Technology, Sydney
}

\begin{abstract}
A constant challenge for scholarly research relates to its impact on and integration into public policy. Where the policy issues are 'wicked', as are those concerning intercultural relations and social cohesion, social science research often becomes implicated in real-world problem solving which occurs within everyday political manoeuvring. This paper takes three empirical problems, and three conceptual approaches, and explores what happens when they are pressed together. In particular the paper explores how together they can enhance the social value of the concept of 'social inclusion'. Cosmopolitanism has a myriad of possible definitions, but is perhaps best addressed in anthropological fashion, by trying to capture the space formed by its presumptive antagonists: nationalism, prejudice, localism, parochialism, and 'rootedness' (as in 'rootless cosmopolitan'). Cultural capital, as developed by Bourdieu (1977, 1986), concerns a disposition of mind and body that empowers members of those particular groups that have the resource in socially-approved abundance to operate the cultural apparatus of a society and therefore the power system, to their mutual and individual benefit. Social capital, removed of the vestiges of Marxist class analysis that lurk in Bourdieu's explorations of education and social power, harks back to another sociological forebear, Emile Durkheim. Durkheim's vision of modern societies saw them as being on the edge of incipient catastrophes resulting from anomie and alienation, unless they could renew and reinvigorate their "conscience collective". Such a sense of the importance of collective solidarity has influenced, through the ideas about social systems developed by Talcott Parsons, the work of American Robert Putnam, whose leading Australian disciple has titled his book on the theme of social capital, 'Disconnected' (Leigh 2011). Having examined these concepts the article applies them sequentially to three cases of state/civil society relations, through (a) the February 2011 People of Australia multiculturalism policy, (b) the place of young Muslims in Australian society, and (c) the place of Chinese Australians in the Australian polity. Finally it is argued that the concepts are most useful when they are applied to analyses that reveal rather than conceal hierarchies of social, cultural, economic and political power, through an examination of the possibilities of democratic inclusion.
\end{abstract}

\section{Introduction}

At the height of the grip of multiculturalism on Australia policy in the late 1980s, two senior scholars with an involvement in public policy on cultural diversity confronted one another over the future of that policy's framework. Stephen Fitzgerald, former ambassador to China, polymath and diplomat, scholar and advisor to government, brought down a report on Immigration and Population to the Immigration Minister Robert Ray that argued 'multiculturalism' should be dropped as a descriptor and indeed a concept, with a policy orientation more based on cosmopolitanism to be adopted in its place (Fitzgerald 1988). Across the corridor as it were, Peter Shergold, former (and in 2011 once more) academic and economic historian, was sponsoring in his role as head of the Prime Minister Bob Hawke’s

\footnotetext{
${ }^{1}$ I acknowledge the feedback and engagement from colleagues at the Queensland Academy of Social Sciences in Australia symposium on cosmopolitanism in April 2011, and in the cosmopolitanism reading group in the Cosmopolitan Civil Societies Research Centre at UTS, in June 2011.
} 
Office of Multicultural Affairs, the development of a report on the future of multiculturalism that would advocate for a Multiculturalism Act, and the embedding of social justice as a key parameter of policy. Shergold was to win that encounter, though not all elements of the battle it initiated, ambushing Fitzgerald and leaving the coterie of Fitgerald's ministerial supporters undone (Jakubowicz 2009b). While the politics are fascinating, more interesting are the theoretical domain assumptions about the social realm revealed by the stoush, and therefore the role of humanities and social science scholarship in informing the contesting deep structures of thought underpinning contemporary Australian governmentality.

This article is driven by an interest in how scholars conceptualise the social, and how reflexively aware they are of this process. It is also driven by a concern that the proliferation of social theories about these issues reflects, as one nameless public servant once put it to the author, the emphasis on the post-hoc rationalisation conveyed by the ironic terminology 'policy-driven evidence', rather than the reverse where theoretically-inflected and carefully considered work on researching social problems produces well-weighed evidence for the pathways of policy chosen. Nowhere has the confusion about policy and its engagement and resolution of social problems identified by both scholars and public debate been more apparent than in the field of cultural diversity relations.

The production of knowledge in the social sciences occurs within a political economy that reflects in many ways the wider social context; as intellectuals, academics are located within a competitive market-driven environment where increasingly their reputation (the major economic resource and the central component of academics' cultural capital) fashions life opportunities. Research occurs in a 'real-world' setting, where pressures towards conformity of thought and deed interact with the opportunities offered for innovation and experiment.

In recent research projects, I have been drawn to use three conceptual 'thought-nodes' to explore empirical dimensions of Australian diversity. Colleagues at the Cosmopolitan Civil Societies Research Centre at the University of Technology Sydney have been developing research conversations around the use and value of 'cosmopolitanism' as an analytical framework. My research in this regard relates to the experience of wartime refugees from Europe residing in the cosmopolitan city of Shanghai (Jakubowicz 2009a) and also in relation to the Fitzgerald/Shergold contest discussed above about multicultural policy (Jakubowicz 2009b). In contracted government research drawing on a requirement to use a methodology 
including a social ecology approach, our research team has adopted/ adapted Pierre Bourdieu's (1977) idea of cultural capital to analyse the situation of and appropriate policy responses to the knowledge cloud enshrouding/ engulfing/ empowering/ constraining young Australian Muslims (Jakubowicz, Collins and Chafic 2011, Collins et al. 2011). One implicit dimension of the values/practices question raised in this research points to cosmopolitanism as a 'repertoire of values' captured by the idea of 'disposition' developed by Bourdieu. In addition, both these concepts, and the idea of social capital borrowed from Putnam (1995, 2007), have been applied to exploring the Chinese dimension of Australian politics and diversity (Jakubowicz 2011a, 2011b).

Are the social relations being analysed only called into existence by voicing them within particular theoretical parameters? Is there a 'social something' that cosmopolitanism, cultural capital, and social capital each illuminate from their own trajectory? That is what I am seeking to discover. Given the importance of systemic models of the social realm, the policy debates with which I am concerned inevitably are framed by discussions of social inclusion, social cohesion and social marginalisation. The big 'C', Cosmopolitanism, with its huge literature and range of perspectives, provides the first portal into this problem.

\section{Cosmopolitanism: analytical, empirical, philosophical, ethical?}

Cosmopolitan(ism) has multiple intellectual forebears and has 'form' in many different contexts. In the same way we may distinguish between 'multicultural' as a descriptive term referring to a multiplicity of cultural groups within a society, and 'multiculturalism' as variously a political program and a philosophy of social relations, so cosmopolitan also needs to be separated into its different conceptual elements. Cosmopolitan can refer adjectively to a society, and to a perspective on the world, and as a noun to people who adopt such worldviews, or indeed live in such societies. Cosmopolitanism refers however to a philosophical or ideological take on the form of social relations suited for a complex and culturally diverse society or world.

The distinction between multiculturalism and cosmopolitanism lies in exactly those unspoken values at the heart of the Shergold/ Fitzgerald dispute described above. The distinction emerges partly dialogically, as a consequence of the clash of domain assumptions of the protagonists about the nature of the social, and partly politically through the institutional interests that they are seeking to advance, defend, or attack. 
Ulrich Beck, a European advocate of cosmopolitanism, in his discussion of the desirability of a 'new cosmopolitanism' (Beck 2007 : http://www.signandsight.com/service/1603.html) offers (in a slight parody of nineteenth century German philosophy via Marx’s theses of Feuerbach) seven theses against global capital. He proposes that we can only understand the global inter-relatedness of societies and peoples from a 'cosmopolitan perspective', the adoption of which he describes as ‘cosmopolitanisation’ (Beck 2002). This perspective arises from the 'erosion of distinct boundaries dividing markets, states, civilizations, cultures, and not least of all the lifeworlds of different peoples'; it occurs inside societies in the mundanity of the everyday (and is echoed in a different key in the idea of ‘everyday’ multiculturalism). Furthermore, "It is a question of inverting Marx's basic idea: it is not that being determines consciousness, but instead that consciousness maximizes new possibilities for action (cosmopolitan perspective)”.

Beck goes on to summarise his sense of the distinctiveness of the cosmopolitan from the multicultural:

Multiculturalism... means that various ethnic groups live side by side within a single state. While tolerance means acceptance, even when it goes against the grain, putting up with difference as an unavoidable burden. Cosmopolitan tolerance, on the other hand, is more than that. It is neither defensive nor passive, but instead active: it means opening oneself up to the world of the Other, perceiving difference as an enrichment, regarding and treating the Other as fundamentally equal (Beck 2007).

This setting of multicultural against cosmopolitan, with the former portrayed as essentially a minority-sought apartheid versus the latter's ostensible vision of an inclusive engagement with cultural diversity, marks the heartland of the European policy debate. Multiculturalism's opponents are in evidence most vividly in the 'Multikulti ist Tot' soliloquy from Germany's chancellor Angela Merkel, the distancing of British official discourse under the Prime Minister David Cameron, and other moves in Holland, Denmark and France towards a more monocultural vision of cohesion (Jakubowicz 2011b). Beck voices as it were an anti-capitalist version of the pro-capitalist policy position of the European leaders. However opposition in Europe to multiculturalism does not necessitate support for cosmopolitanism, which may meet equally rancorous opposition. 
Australian scholarly discussion and research on cosmopolitanism has demonstrated the complexity of the term, including its potential to be seen as ideologically neutral and analytical, rather than programmatic. Both Woodward Skrbis and Bean (2008) and Phillips and Smith (2008) have sought to operationalise cosmopolitanism as a set of specific values, beliefs, attitudes and practices (qua Bourdieu’s ‘disposition of mind and body’, one of three dimensions of cultural capital).

Woodward et al. have used the 2004 Australian Election Study to problematise the relationship between cosmopolitanism and globalisation. They find that there are at least three types of 'cosmopolitanness' in Australian society, each factor cluster being associated with different (though somewhat overlapping) social groupings. The first cosmopolitanism, 'consumptive', refers to the appropriation of the cultural objects of the Other for one's own use (especially cuisine and tourism); in Australia an overwhelming majority of people are happy to do this. The second, economic cosmopolitanism, appears less evident where people are less comfortable with the endorsement of neo-liberal movements of people thought of as 'human capital'. They do not so readily accept the alleged benefits of economic globalisation, even where they are strong consumers of 'ethnic' food, music and other cultural artefacts. Thirdly, a significant group sees globalisation as having strong human rights benefits, facilitating the spread of cosmopolitan human values. The authors also explored the demographic predictors of support for cosmopolitan values. Economic cosmopolitanism was more likely to be supported by younger than older people; more by managers, less by professionals; more by Protestants, less by other or no religions; more by non-Anglo immigrants, less by Australian born. In relation to global rights, stronger support is evident among the young, women, and non-Anglo immigrants. Concluding the study, the authors suggest that "cosmopolitan outlooks develop from the expression of universal sentiments to which most in the globalizing world have access, but they are also ruptured and skewed by the peculiarities of discourses within the nation” (2008, p.224): that is, there can be no singular universal cosmopolitanism, just variegated national ways of orienting oneself to the world from within a cosmopolitan frame of mind.

While Woodward et al. (2008) interrogate the attitudes and values involved in cosmopolitan dispositions, Phillips and Smith (2008) ask how might such values (conceived of as an 'outlook') link into what could be seen as cosmopolitan practices. Their practice indices include visits overseas, long-distance conversations overseas, friends outside Australia, hours 
of daily Internet use, and watching SBS television (the national multicultural broadcaster). Outlook was tested by asking respondents to place themselves on a social distance scale in relation to Indian, Greek, Aboriginal, Lebanese and Vietnamese Australians. The authors concluded that their respondents were high on cosmopolitan outlook, but their practice was significantly lower; however they argued that if you were high or medium on practice, you were very much more likely to hold to a strong cosmopolitan outlook. In addition, cosmopolitan outlooks were more likely among people who were non-religious, welleducated, and younger (and they of course would be more likely to 'practice' cosmopolitanism).

The third dimension of cosmopolitanism identified by Woodward et al. (2008), manifested through the ideas associated with human rights, has become the most problematic in relation to multiculturalism (the latter of course otherwise sits comfortably with consumption of diversity, and neo-liberal economic and labour market policies). Human rights are generally thought of as universal; that is, independent of any specific culture (though they have been contested especially by China and Malaysia as being from a western, neo-colonial and culturally biased perspective). To what extent, we might ask, does cosmopolitanism go beyond recognising other cultures as 'fundamentally equal', to accepting cultural difference as a legitimate basis for refusing to apply general human rights criteria? That is, how does the universal perspective of cosmopolitanism deal with cultural approaches which express values that contradict common (Western or global?) standards of human rights?

Fitzgerald's critique of multiculturalism was that it did in fact permit if not legitimize cultural differences that were in conflict with human rights; he held that universal human rights trumped multiculturalism's cultural relativism, and thus multiculturalism should no longer hold dominance as an ideology of egalitarian inclusion (a task at which he suggested it had in fact failed). Shergold's defence of multiculturalism was predicated on a framework that took fundamental human rights for granted as the sine qua non of Australian democracy. Fitzgerald's cosmopolitanism promoted the need for wide societal acceptance of the value of diversity and appreciation of different civilisation histories, while foregrounding AngloAustralian mores as the bedrock of the society (in that these values were indeed what made it possible to be cosmopolitan). His recommendations for Australia's immigration program proposed it should be based on a 'points system' that privileged immigrants with cultural capital that accorded with mainstream views of Australian society, and the needs of the 
Australian economy. Shergold might well have argued that cultural integrity would be dissolved if multicultural norms were not asserted; the focus here would be on retaining and enhancing family reunion. It is important to acknowledge that neither actor advocated assimilationism, both accepting the importance of social dynamics that should integrate immigrants into the 'democratic civility' of Australian society. Essentially if we unpack their discourses and use them together to interpret the scene, it appears that multiculturalism as a policy and set of practices protects ethno-cultural groups from the destruction of their cultural institutions brought about through temporal erosion or active host-society assimilation policies, through permitting and facilitating but not requiring a trans-generational inculcation of ethno-cultural mores. Cosmopolitanism sees no particular value in such interventions, but does see the inculcation of reciprocal recognition and respect within and between ethnocultural groups through their trans-cultural endorsement of human rights as a critical social cohesion feature of societies caught up in the irresistible dynamic of globalisation. In (my) summary, for Fitzgerald, the multiculturalists were self-serving rent-seekers uncaring about social cohesion; for Shergold, the cosmopolitans were Anglophile elites bent on forcing Australian diversity into something quite limited and suited to their aesthetic sensibilities to sustain their power and resist the threats of diversity to their hegemony over political, cultural and social power. This brings us directly to the concept of 'cultural capital' and its infusion of the debate about inclusion with questions of power, interest, and super-ordination.

\section{Cultural capital: a disposition of mind and body, and the power to do something about it}

The concept of cultural capital, drawn from the work of social philosopher Pierre Bourdieu, reflects the sense of 'investment' and the associated cultural 'goods' that enable social mobility and access to power within a society. Bourdieu refers to cultural capital having three dimensions, namely the embodied state of long lasting dispositions of the mind and the body, secondly the cultural objects that 'objectify' a society's cultural value, and thirdly an institutionalised context where society rewards some forms of cultural capital while ignoring or de-legitimating others (Bourdieu 1986). Cultural capital represents the objectified forms of cultural production, the 'store of cultural value' built up within an ethno-cultural group over time, circulated and transmitted inter-generationally through socialisation and education. It includes social knowledge, and the instruments to sustain and communicate that knowledge. One manifestation of cultural capital must surely be found in the 'perspective', world-view or 
weltanschauung that individuals and groups bring to bear on identifying, interpreting and understanding their world.

For immigrant communities, the acquisition of new cultural capital necessary to gain purchase on their new world has to be accommodated within the cultural frameworks they carry with them from their previous lives. Some sub-cultures and class-based cultural repertoires, especially those associated with super-ordinate social classes or strata, are more experienced or better-oriented to do this than others. The capacity to 'open oneself up to the world of the Other' and appreciate the equality of the Other's culture requires a particular enabling 'long-lasting disposition of mind', that is, a particular fragment of cultural capital, though the conditions of its possibility may be carried in other fragments (eg Englishlanguage skills). The process of immigration, settlement and integration requires both that one have this pre-existing disposition of self-opening, and also the capacity to modify other pre-existing dispositions and internalise new ones. Now it may be argued that voluntary emigrants from a society are exactly those people who have already such an incipient disposition, indeed that the disposition is one of the drivers for emigration. Migrants then may well be the groups in a society with the most pre-wired fragments of cultural capital in relation to bearing a cosmopolitan perspective, both because their mundane lives are already interwoven with the realities of 'internal globalisation', and because they have decided to some extent to move social worlds, even if choosing to buffer the necessity of choice by seeking to reside in communities and neighbourhoods of like-minded people from their cultural location of origin. However such an optimistic reading needs to be offset by examining to what extent other elements of their cultural capital interpret their new world as one to which they wish to become 'open'. Indeed the response to the immigrants' arrival, by the various fragments of the receiving society, will demonstrate how and to what extent the cultural capital the immigrant brings is valorised in the receiving society, by whom, and with what implications.

A particularly apposite example can be found in the processes through which 'overseas' qualifications are recognised or rejected; these qualifications represent enormously significant stores of personal cultural capital, the value of which is heavily dependent on whether they are acknowledged to have cultural currency in the new society. Christina Ho (2004) points to the importance of qualification recognition by the host society in the settlement experience of skilled women immigrants from China and Hong Kong; the latter 
were far more advantaged by three factors - they were English speaking/writing; they had experience of working within western capitalist enterprises; and their qualifications were far more readily acceptable (indeed they sometimes simply transferred into Australian jobs with multi-national corporations for whom they had worked in Hong Kong).

Some of this debate has been foreshadowed by Ghassan Hage's examination of the Fitzgerald Report and his construction of the term 'cosmo-multiculturalism' (2003) (I would argue a mis-reading of Fitzgerald) and the critique of this reading by Scott Brook (2008). However I want to think about how cosmopolitanism as a fragment of cultural capital might be understood in different segments of Australian society; how it might be acquired, and what import it delivers to individuals and groups competing for access to wider social power (and the capacity thereby to have greater control over their life chances). I return to an application of this approach below, but first set out the logics associated with the 'social capital' approach.

\section{Social capital: the production of trust and the (social and theoretical) problem of social cohesion}

The social cohesion and social inclusion discourses come from a rather different spaces in the sociology of social policy, though the terms have slipped effortlessly and often confusingly into popular debate. The Australian Parliament’s Joint Migration Committee inquiry into Migration and Multiculturalism (2010-2012) opens with a question about the optimal relationship between multicultural and social inclusion policies.

Melbourne's Scanlon Foundation has pumped significant funds into the Monash research project on Social Cohesion, whose director Andrew Markus has argued that the trend line in social cohesion was continuing to rise through 2007 to 2009, but dropped dramatically in the period 2009 to 2010. The Scanlon work derives its questions from the literature on social capital, evident in this comment by Markus:

The 2010 poll registered change across indicators of rejection and social justice. Those in agreement with the proposition that 'most people can be trusted' fell from 55 per cent to 45 per cent. Those who reported involvement in 'unpaid voluntary work', which was defined in the survey as 'any unpaid help you give to the community in which you live, or to an organisation or group to which you belong', fell from 38 per cent to 32 per cent (Markus 2011). 
The key operational elements of social capital theory - trust and volunteering - are drawn from the work of Robert Putnam (e.g. 1995, 2007; Portes 1998).

Given that Bourdieu also uses the concept of social capital, it is worth sorting out how the term can be distinguished in the approaches of these French and US scholars. Siisiäinen (2000) points to the underlying sociological domain assumptions that shape their arguments. Bourdieu uses 'social capital' as one dimension of a tri-partite model of capital: cultural (as above), economic and social. In a sense Bourdieu refashions Weber's ideas to position social capital as the resource base for the realm of political conflict and social dominance and resistance. Putnam comes out an American pluralist tradition, affected by Parsonian models of consensus and social integration, drawing ultimate inspiration from Durkheim. For him social capital is built through supportive interactions, creating bonding capital within groups, and bridging capital between them. For Putnam, both are necessary - too little bonding capital and people become isolated and marginal; too little bridging capital and groups become separated and even potentially conflictual. Social capital that strengthens society does so through producing trust between people and groups as one of its outcomes; such a trust-rich society would be one with high levels of social cohesion, in which the population were included effectively in the material and non-material rewards of participation and sociability.

Social inclusion (as developed in Australian government social policy discourses such as on http://www.socialinclusion.gov.au) sounds like social cohesion, but in fact seems to be about some other problem; in practice it refers to groups and individuals who do not appear to possess adequate or the 'right' range or type of cultural capital (education, world views, saleable skills, emotional flexibility, focus on employability etc.) for autonomous survival in contemporary neo-liberal capitalist Australia, thereby failing to flourish. Frustration with the failure of the government's social inclusion strategy (PM Gillard was social inclusion minister for 3 years) seems to be a driver for renewed government discourses about hard work and contributing to society, echoed in UK PM Cameron's castigation of immigrants as welfare system abusers. So the decline in social capital, in this logic, can be attributed to the inadequacy of cultural capital of those marginalized in the broader economic system. Why is the cultural capital inadequate? For Cameron it is a consequence of immigrant cultures (read Muslim). For Gillard it appears to be lack of self-discipline. In both cases one can deduce an anxiety that social cohesion (read the social order in Bourdieu's terms) is threatened by those 
who have insufficient social responsibility, that is, insufficient willingness to see themselves as part of a wider society, incapable of 'opening themselves up to the Other' where the Other are those who are empowered by their cultural capital, and effectively control the range of social capital validated by the political system.

\section{The Triangle applied 1: policy}

Given my theorisation of the relation between the master concepts ('the triangle'), I now want to bring them together as tools to reflect on three empirical problems. These problems reflect distinctive research contexts, employing different methodologies, but illuminated by the triangle's glow. The following diagram points to the problematic space of 'democratic inclusion', that seems to be the area where the concepts compete for purchase and explanatory power. By democratic inclusion I mean a space of respectful interaction among equally-valued citizens, in which both rights and responsibilities are broadly shared and understood, and in which reciprocity underpins social interactions (Honneth 1995).

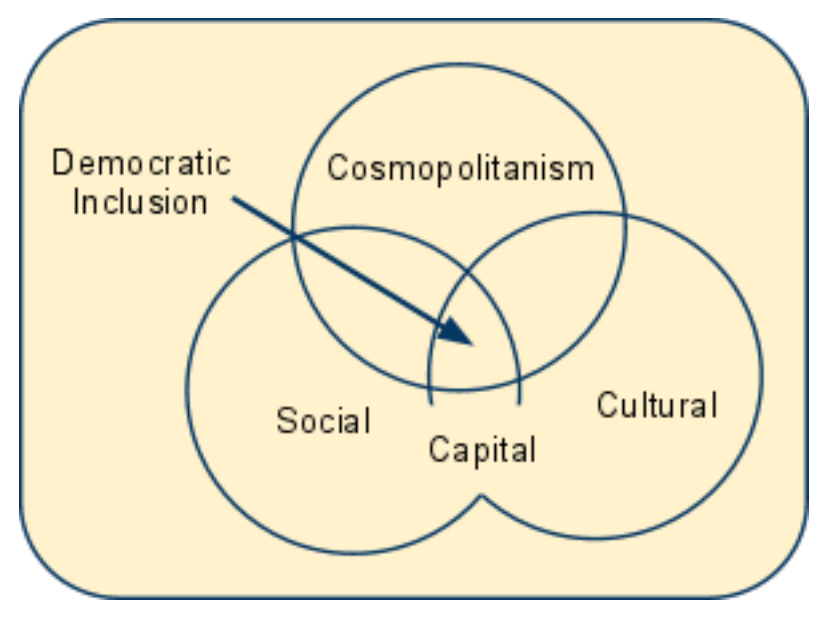

The Venn diagram refers to social spaces claimed in the different theoretical discourses discussed above, which overlap in terms of practices they claim to explain and/or control. The diagram thus refers to a theory/governance relationship, and thus becomes an expression of modes of governmentality. The overlap between them all, I suggest, can best be captured through the idea of 'democratic inclusion'; 'democratic' because it can be approached for all society's members through processes of political participation, 'inclusion' as it interprets society as a complex system of interacting and interdependent often unequal relationships, that can be more equitably resolved though processes that foreground reciprocity of recognition of the Other’s legitimacy (Honneth 1995; Deranty and Renault 2007). A public policy that ostensibly seeks to advance democratic inclusion offers a useful starting point. 
The announcement of a national Multicultural policy in February 2011 by Immigration Minister Chris Bowen (Bowen 2011) at the conservative Sydney Institute took outsiders to the machinations of government somewhat unawares (though the policy histories have been well documented by Roth 2007 and Koleth 2010.) The Australian Multicultural Advisory Council 2010 report to the government 'The People of Australia' had asserted the need for national leadership and an anti-racism strategy but had not supported submissions to it to resurrect the 1989 push for a Multiculturalism Act, nor the re-establishment of a national research and policy institution, nor the re-affirmation of social justice (the pillars of the Shergold strategy of 1989/90 discussed above). Its recommendations were not part of the ALP's 2010 election platform, while after the election the title of Multicultural Affairs had been stripped from the relevant Parliamentary Secretary.

However the February announcement which essentially accepted the AMAC report and gave it some shape, reinstated the Multicultural Affairs label, gave particular acknowledgement to the role of the Federation of Ethnic Communities Councils of Australia's (FECCA) 'Reclaim Multiculturalism' campaign, and made a direct comment about the inappropriate policy positions taken by the rejectionist Europeans. The policy document printed and circulated in April 2011 gives us a 'text' to examine (Gwenda Tavan offered a first summary and critique of the document on The Conversation at http://theconversation.edu.au/articles/why-chrisbowen-isnt-afraid-of-multiculturalism-but-others-are-1043).

What does the policy tell us about cosmopolitanisation in Australia? To what extent does the policy recognise the 'opening self to Other' standpoint, or the nature or social benefit of a cosmopolitan perspective on the world? How have ideas about cultural and social capital been referenced in the policy?

To begin, this multicultural policy asserts its goals of cultural diversity. Whatever these diverse cultures are, they remain apparently unchanged and unchanging. There is no suggestion of wider cultural change as a result of cultural interaction; rather it 'allows those who choose to call Australia home the right to practise and share in (emphasis added) their cultural traditions and languages'. The preposition 'in' gives it away: it is not about sharing their cultures with other people, but rather remaining within their cultural frame of choice, constrained only by the national legal framework. On the other hand, diverse cultural 
expression is said to 'enrich all Australians'. The only detail as to how they are enriched comes from a reflection on economic, trade and investment benefits, and the competitive advantage that accrues from the multilingual workforce. In fact the national is paramount, with diversity subordinated to the national interest, and shared core values presented as the bedrock of the nation. In the hierarchy of cultural capital expressed in the policy, cultural minorities have to subordinate their values to those of the wider society as expressed through the legal structures. Thus anything that is not forbidden is permitted: the heartland of liberal democratic theory. The model is designed to reassert the cultural capital enshrined in the dominant social mores. Multicultural grants are now to be targeted to 'multicultural arts and festivals’, possibly away from the previous focus on de-radicalisation of Muslim youth. Multicultural arts 'encourage social cohesion and mutual understanding', to be achieved through community groups expressing 'their cultural heritages and traditions'.

While the rhetoric remains that 'multiculturalism is for all Australians', the practice appears to be ethnic community-focused. It is only when we come to the new anti-racism partnerships in which we find a strategy that asserts a zero-tolerance position on racism and discrimination, that a denser sense of social theory is discernible. Here we begin to see the influence of social capital theory, with an emphasis on expanding networks, enhancing leadership capacity, and developing and implementing strategy. The concern to build the influence of anti-racism perspectives as part of social change in Australia suggests an awareness that robust cultural capital would necessarily underpin such as strategy.

So where are the problem areas from the perspectives we are exploring here? Firstly discussion of power is notably absent, especially cultural power. Cultural power in Australia draws on education, institutional leverage, 'national legal framework', English language skills, and elite cultural networks. In each case the policy remains silent; no legislative rights framework (ie national legal framework) for advancing cultural diversity, no national language policy, no mention of longer-term resources for English language acquisition, nothing about the role of the media, no strategy for ensuring that input into the multitude of government advisory bodies reflects the diversity of the society, no rescission of Australia's reservation (on the criminalisation of race hate) on the International Convention of the Elimination of All Forms of Racial Discrimination (ICERD) Article 4, and no knowledge creation strategy that places cultural diversity within the national curriculum and at the heart of policy collaborative development. Instead we get a solitary focus on bridging social 
capital, to be carried forward by the Australian Sports Commission in the arena of youth sports, a 'proven strategy to build social and community cohesion' (though no evidence or proof is offered in support).

Drawing together the point of intersection of cosmopolitan, cultural and social capital theories does throw useful analytic light on the missing link in the policy, namely the lack of concept and investment in democratising cultural capital and empowering processes of reciprocity and 'opening up to the Other'. The core culture (always conceived of as a singular entity rather than riven with contradictions, sub-cultural permutations and geo-class differences) need not change, merely desist from responding in racist and discriminatory ways to groups who are free to follow their own cultural forms (that is, nurture their own cultural capital), unless these breach the law.

\section{The Triangle applied 2: social ecology}

Introducing his recent edited essay collection on Muslims in Australia, philosopher Raymond Gaita writes:

The response to Muslims after September 11 would not have been the same if most Muslims were white. Fear of them tapped into a strain of Australian racism that runs deep....Nothing, indeed, goes deep with 'them' as it does with 'us'. That is what makes them 'them', and the fact we are not like them, makes us 'us' (Gaita 2011, p.15-16).

My research group at UTS tendered for and was successful in securing a contract from the Australian Government Department of Immigration and Citizenship (DIAC) for a project on the Influences on Muslim Youth, to be conducted within a framework of social ecology. None of us, or indeed the Department by the time we began the project in 2009, was exactly sure why the social ecology approach was required, and what specific advantage might flow to the National Action Plan from insights it generated. However it became clearer as the project developed that social ecology, which locates social actors in an ever-expanding set of layers of influences and interactions, would become critical, especially where effective program interventions would need to be salient and compelling for the people addressed. Social ecology can best be understood as a metaphorical device that connects the global to the local, to the intimate spheres of experience and influence on people's lives, attitudes and practices. 
This project along with maybe a dozen or more over the previous few years, had been funded by a Budget tranche that was a consequence of two major politically paradigmatic events the Cronulla riots of 2005, and the London 'home grown' bombings of 2007 (http://www.immi.gov.au/media/publications/multicultural/). The Howard government carried out a national consultation with Muslim leaders and representatives in 2006, which exposed the dearth of information about the lived experience of Australia's diverse Muslim communities, and the by-passing of their needs by government programs. In addition the national Living in Harmony funding program had been pointed towards inter-faith projects, and then tightened to focus on the de-radicalisation of Muslim youth and their integration into the Australian mainstream. By the time the ALP took control of the portfolio under Laurie Ferguson as Parliamentary Secretary in 2007, DIAC’s Multicultural Affairs section was working closely with the Australian Federal Police (AFP), the Australian Security Intelligence Organisation (ASIO) and the Department of the Attorney General (AG) on a broad approach to identifying, de-mobilising and diverting potential participants in Muslim jihadism in Australia. Two competing administrative philosophies were in place in the same space; that of anti-discrimination and social integration of young Muslims, and that of surveillance and incarceration, described in the UK as the tension between programs labelled ‘Community Cohesion’ and ‘Prevent’ (Husband and Alam 2011).

Social ecology as we began to elaborate it, gave us the opportunity to explore the sociocultural worlds of young Australian 'Muslims' (a term requiring deconstruction as it refers to belief, ritual behaviours, identity, labelling, and social relationships). Increasingly we returned to the value of Bourdieu's 'cultural capital' to analyse the issues we were seeing. If integration, the catch cry in policy, refers within this theoretical space to the acquisition of social mores, world views and public behaviours that 'lock into' pre-existing mores in the non-Muslim world, then we were in fact exploring the constitution of cultural capital and its investment, circulation and expenditure in multiple layers of association. This is not the place to report the results of this research (see Jakubowicz, Collins and Chafic 2011) but rather to reflect on the analytical purchase of the concept of cultural capital in such a poly-religious and multi-ethnic society as Australia.

Our research used two main methods - a survey of 300 or so young Muslims (all in situations where espousal of religious identity would be a taken-for-granted reason for being there - Eid Il Fitr celebrations and Muslim schools) and extensive focus groups with gatekeepers (from 
youth workers to musicians), professionals, and specific groups of young Muslims from different ethno-national backgrounds in Sydney, Melbourne and Darwin, with a few individual deeper interviews. The vast majority of youth surveyed were Australian born, the majority from Lebanese families. They were in general well-educated, and overwhelmingly reported pious life styles. To capture the dynamics through which cultural capital was acquired and elaborated, we explored a range of influences.

Who were their role models? To whom did they turn for advice - family, friends, religious advisors, the Internet/media? What web sites did they use, and what media did they consume? Did they have facebook or Bebo pages? Did they belong to Muslim or non-Muslim organisations or both or neither? What had been their experience of discrimination and where had this occurred? How diverse were their friendship networks? How did they manage interaction with non-Muslim friends in situations that might challenge Muslim mores (eg serving alcohol, non-Halal food)? Did they identify as Muslim, Australian, or MuslimAustralian?

Our focus group panels took us through comedy and film, the outer-edges of Muslim youth culture and to the challenges of orthodoxy, interpretation and creativity. What musical instruments were halal, which haram, and why? For those who were Sufis, how comfortable were they where other Muslims might be Salafist? For young people with gender identity questions, how were these managed? What about mental health issues and community approaches? How would they rank values (drawn from the World Values Survey)? The research was complex, fascinating, and intellectually challenging, as we were writing to a government agenda, one that was changing but which had as its distant backstop an alert for anything that might cause public concern and outrage against the Minister.

Moreover it became increasingly clear to us that Muslim youth were diverse, contextually responsive, sub-culturally involved and quite socially engaged (as the majority were attending Muslim schools, many took part in community-related activities whether directly or through mosque-based groups). In our sample, as might be expected, social and moral views were conservative, with high personal aspirations. The young people expressed strong awareness of the marginalizing processes impacting on them from the wider society, especially the media. Many had experienced discrimination in the public education system, in public places and at work. Muslim schools represented a far safer if socially constrained 
space; they instilled pride in Islamic cultural and history, and a strong affirmation to be treated as equally Australian.

Their cultural capital can be seen as a constantly evolving stock of skills and understandings that emerge from an interaction between their 'Australian' worlds, and their ethno-religious one. In that process they have to manage the sustained barrage of what they perceive as mainstream 'delegitimation’ of their cultural capital (effectively reducing its 'currency’); for some this means they pro-actively press themselves into situations where they can demonstrate a Muslim-inflected Australian modernity, for others it creates barriers from which they retreat into ethno-religious enclaves, for others still it contributes to isolation, alienation and bitterness. The inter-active dynamic to which Gaita refers above, in which Islam is racialised and visual racial difference becomes synonymous with religion, feeds the process of legitimating and delegitimating the cultural capital that young Muslims share.

Are young Muslims more or less likely to hold to a cosmopolitan perspective, given Islam is both more world-encompassing than any individual national identification, though not necessarily 'inclusive' of non-Muslims? Are they, because of their intimate immersion in both Muslim and non-Muslim social worlds, better attuned to opening up the self to the Other? Does their awareness of a global Islamic Ummah of which they are a part, reduce their feelings of nationalism and identification with the Australian state? On the other hand, does their association with Islam reduce their capacity or willingness to engage outside-thefaith communities as other than combatants (intellectual rather than terrorist)? Do they express a reciprocal respect for those who are ethno-culturally different from them, or do they hold to a binary divide between Muslim and Infidel/non-believer?

Muslim communities make serious investments in the building of social capital, developing internal relations of trust, in the face of a distrustful external environment. It is not surprising therefore that bonding capital measures turn up very high scores for Muslim youth; Muslim organisational membership, volunteering in community enterprises, coaching younger children in religious classes at mosques, and raising funds for Muslim charities are some examples. While Putnam may see social capital dissolving in advanced capitalist societies such as the US, expressed through the decline in voluntary organisation membership and volunteering, the opposite seems to be occurring among the subjects in our research in relation to bonding within communities. However bridging social capital is far harder to find, 
though inter-faith groups and participation in non-Muslim organisations are still apparent. The process of constituting bonding social capital seems to increase the legitimation and deepens the community focus of cultural capital. As NSW noticed in the March 2011 state election, the entry of Muslim young leaders into the Liberal Party and their empathy with its conservative moral program swung a substantial part of the Muslim community towards the Coalition, delivering (along with the Chinese vote) a swag of unanticipated victories to the Party in Sydney’s Western and South Western suburban so-called Green Crescent.

Chinese and Muslim/Arab localities abut and indeed overlap in suburban Sydney. We turn now to the Chinese communities of Australia, especially those engaged in local and state politics in NSW. The epicentre of the Chinese communities has become Ashfield, with its main street sometimes stereotyped as 'little Shanghai’ (Wise 2005).

\section{Triangle applied 3: the Chinese in Australian politics}

Pan Ling writes, in 1982, nostalgically reflecting on the Shanghai of pre-1949:

Shanghai was cosmopolitan. There were really two Shanghais - the foreign and the indigenous. Early European visitors to the city often remarked that Shanghai was not Chinese...For millions of Chinese, its name was synonymous with trendiness... For it was, to the popular Chinese mind, the capital of style (Pan 1982/1991, pp. 3,5).

I have had a lifelong fascination with Shanghai, where my refugee family survived the Holocaust. My parents crept into Australia through a small window opened in 1946 by then Immigration Minister Arthur Calwell, before he capitulated to anti-Semitism in post-war Australia, while also embarking on his ex-fenestration of Chinese refugees who had found haven in wartime Australia. My parents' stories were full of adventure and excitement, interspersed with the sudden silences of survivors when they caught themselves thinking of those who had perished (Jakubowicz 2009a).

My parents would fit many of the positive and negative definitions of cosmopolitan. They were children of a secular Jewish generation growing up between the Wars in the new nation of Poland, living a bourgeois educated lifestyle in one of the country's great industrial cities. My father's family spoke German, Russian and Polish, and he was educated in Vienna at the fachhochschule that today still carries an early twentieth century carving of an Australian 
Aboriginal face (among other global peoples) on its pediment. As an adult he spoke English, French, Yiddish and the other languages; he was trained in the global language of mathematics, and worked as an accountant. My mother was educated in Warsaw in political economy, and suffered under the anti-Semitic fascist taunts of the Polish Endeks (National Democracy Party) who would become infamous as collaborators with the Nazis after 1939. She then became production manager on a Polish newspaper in her hometown of Lodz, also speaking French, Russian, English and German. For Hitler they were Asiatic Jews, for Stalin rootless cosmopolitans, for the Japanese who interned them in Shanghai, stateless émigrés, and for the Australian government suspect aliens of the Hebrew faith. This all by way of a slight detour, better covered in my website 'The menorah of Fang Bang Lu' (http://research.hss.uts.edu.au/ShanghaiSite).

By happenstance, in 2008 I took up a new position at the University of Technology, Sydney as head of the Social and Political Change Academic group, which incorporated the China Research Centre (CRC). In 2010 with two CRC colleagues and prompted by the remarkable research into Brisbane's Chinese politics of Jen Tsen Kwok, my research assistant on the Queensland leg of Making Multicultural Australia (http://multiculturalaustralia.edu.au), we developed an (unsuccessful) ARC application. This then led to an academic conference and community symposium on the Chinese in Australia politics in September 2010 (http://cosmopolitancivilsocieties.com/nodes/mcdara/chinpol/ and http://vimeo.com/17991025 ), and a couple of research papers scoping the issues raised for Australian multiculturalism by the Chinese presence (Jakubowicz 2011a, b).

My thesis is that the contemporary Chinese 'moment' represents the first time Australia (since the original British settlement and expansion) has experienced a large population component that is drawn from a major trading partner, so that both the Australian economy and society are significantly affected. Multiculturalism was never designed to address such a situation, so the policy and the residual racism that continues to penetrate and undermine it (also evident with Indians) thus counter-productively erodes the Australian national project. As the quote from Pan suggests and my family story implies, immigrants carry a potential for 'cosmopolitanism' as part of their arrival baggage. This potential requires that certain conditions be activated, associated in turn with their ethno-cultural group, their class and capacities for operating in an urban capitalist environment, their historic experiences and the receiving society, in order for them to flourish after arrival. 
The Chinese presence in Australia reflects not a single ethno-cultural group (determined by some imagined and racialised unitary expression through physiognomy) but rather a great diversity of histories, origins, political attitudes and cultural practices. If we take each element of our Triangle in turn, we can see how this plays out.

Feng's argument (2011), that the PR China (PRC) government has moved from communism to ethno-nationalism as its dominant ideology and strategy for regime survival, suggests that the earlier PRC immigrants (for instance the June 41989 movement Tiananmen escapees) may well have had a more cosmopolitan perspective (with their insistence on universal human rights and democratic reforms) than more recent arrivals socialised under the Han empire ideology guided by Premier Wen Jiabao. But the PRC while dominant is not the only source of Chinese populations. As Kwok (2008, 2011) has demonstrated for Brisbane, the tension between the three arcs of Chinese immigration - Cantonese/Hong Kong, Mandarin/PRC and Taiwanese - emerges from political, cultural, demographic and economic competition. Often it is expressed in the need for interpreters (Mandarin/English/Cantonese) at pan-Chinese meetings.

The formal participation of Chinese in Australia electoral politics is fairly low given their population size; on the other hand Chinese-linked entities and individuals are overrepresented among registered large donors to political parties (Jakubowicz 2011a). One argument has been that their direct political participation reflects a generational issue, with first generation immigrants focussed on putting down economic roots; only later (as for the Greeks and Italians) do they become active in parliamentary politics, usually through the Australian-educated second and third generation. Even so Chinese Australians have gained representation (usually at state level) in periods when race-politics were more salient, especially during the Hanson/One Nation ascendancy in the decade after 1996. During that time in NSW the anti-Hanson Unity Party elected Dr Peter Wong to the Upper House, while Liberal Party Upper House MP Helen Sham Ho left the Liberal Party and sat as an independent. In Victoria Chén Zhībīn was elected to the Senate for the Liberal Party (19992005) winning pre-selection against an incumbent, then losing it next time around. That is, the Chinese were most likely to be successful when the wider social sentiment was more selfconsciously cosmopolitan (paradoxically perhaps if Hanson's ascendancy is our touchstone). The September 2010 Chinese in politics symposium (http://vimeo.com/17991025 at $18 \mathrm{~min}$ 
$30 \mathrm{sec}$ ) heard from Dr Wong, who complained about the disappearance of Chinese politicians from Australian public life. In response a group of younger politicians (in local government) argued that they were now building political careers that were inter-ethnic, suggesting that the cosmopolitan perspective had changed somewhat, to accommodate to a culturally-diverse Australia. Furthermore this cosmopolitanisation in certain areas of Sydney and Melbourne (and Brisbane), complemented by the building of new hybrid Chinese-Australian cultural capital, was increasingly demonstrated in the evolution of bridging social capital between Chinese and other ethno-cultural groups.

We can discern that cultural capital necessary for successful migration and settlement, especially in a diasporic flow that maintains strong links and even opportunities for residence in countries of origin, can be delineated as follows:

- $\quad$ Access to and possession of globally transferable skills and knowledge suitable to advanced economies

- $\quad$ Class-related capacities to operate in an economic system that assumes capitalist economic relations, and corporate modes of thinking and working

- $\quad$ Aspiration for globally-relevant ‘cosmopolitan’ virtues, including education, high-culture, multi-lingualism and professional career ambitions

- Language skills relevant to the settlement society

- $\quad$ Knowledge of ethno-community resources

- $\quad$ Capacity to mobilise the economic potential of kin and ethno-cultural community networks.

While not all of these factors are necessary in every case, they do point to the interaction of cosmopolitan perspectives, cultural capital and social capital (especially trust-based bonding capital and access to bridging social capital), both as useful theoretical tools, and as practical expressions of lived reality. They may also help to explain why Chinese has been hailed as a critical language for Australia's economic and regional future in the national government's language policy paper (http://www.deewr.gov.au/schooling/NALSSP/Pages/default.aspx), but Arabic has not.

\section{Conclusion}

Three different theoretical paradigms based on rather different world-views and intellectual trajectories have been applied to three different cases of diversity and society - policy, society and politics. The first paradigm (cosmopolitan/ism) refers to a capacity to empathise 
with, interact with and appreciate the different cultural backgrounds and expressions of people within one's own society, and elsewhere. In this, following Beck, I distinguish between on the one hand grudging tolerance of different cultures generated by poly-ethnic proximity and enforced through state management of group tensions, and on the other active welcoming of difference (and implicitly constant transformative resultants of the intercultural interactions).

The second paradigm (cultural capital) refers to the tools available within people's subcultural frames of reference, which enable them to advance their interests in a pluralist society, and thereby generates value for their motile place in a constantly seething social hierarchy. Sub-cultures are generated in complex societies by factors of class, ethnicity and education, and contain both elements enabling activity in the wider society (bridging), and specific elements relevant to the group (bonding).

The third paradigm (social capital) further develops the 'capital' metaphor to describe systemically the strength or weakness, presence or absence, of intra-personal, intra-group and inter-group ties of association. It emphasises the role of trust as an outcome of mutually beneficial interactions, allowing the 'holding together' of social relationships, and enabling longer-term social collaboration.

These paradigms become most useful when they are used as interrogatory approaches to empirical situations, rather than as totalising theoretical models. If they are reconceived as scaled dimensions of social power (from less to more, or limited to expansive, etc.) in culturally diverse societies, they enable us to place groups relative to each other and also test these relativities against wider social power hierarchies. Put more simply they are variables that provide through their interaction, insight into the political sociology of Australia and the dynamics of what might be necessary to better achieve democratic inclusion. They point to the directions that political interventions might need to move in order to be productive of a more democratic, empowering and inclusive social order.

\section{References}

Australia, Commonwealth of 2011, The People of Australia: Australia's Multicultural Policy, Canberra.

Beck, U. 2002, 'The cosmopolitan society and its enemies', Theory, Culture \& Society, vol. 19, nos. 1-2, pp. 17-4. 
Brook, S. 2008, 'Cultural capital and cultural diversity: some problems in Ghassan Hage’s account of cosmopolitan multiculturalism', Journal of Australian Studies vol. 32, no.4, pp. 509-20.

Bourdieu, P. 1977, Outline of a Theory of Practice, Cambridge University Press, Cambridge. Bourdieu, P. 1986, 'The Forms of Capital', in Richardson, J. (ed.), Handbook of Theory and Research for the Sociology of Education, Greenwood Press, New York, pp. 241-258.

Bowen, C. 2011, Multiculturalism in the Australian Context. Speech to the Sydney Institute http://www.katelundy.com.au/2011/02/17/minister-for-immigration-and-citizenshipchris-bowen-multiculturalism-in-the-australian-context/.

Collins, J., Jakubowicz, A., Pennycook, A., Ghosh, D., Cole, D., Al-momani, K., Hussain, J., Chafic, W., 2011, 'Voices Shaping the Perspectives of Young Muslim Australians', Report to the Department of Immigration and Citizenship, CCS, UTS, October. http://www.immi.gov.au/media/publications/multicultural .

Deranty, J-P. and Renault, E. 2007, 'Politicizing Honneth’s ethics of recognition’, Thesis Eleven , no. 88, pp. 99-111.

Feng, C. 2011, 'The changing political identity of the "Overseas Chinese" in Australian Politics’, Cosmopolitan Civil Societies Journal, vol.3, no.1, pp. 121-138.

Fitzgerald, S. Chair 1988, Immigration: A Commitment to Australia - The Report of the Committee to Advise on Australia's Immigration Policies, Australian Government Publishing Service, Canberra.

Gaita, R. (ed.) 2011, Essays on Muslims and Multiculturalism, Text Publishing, Melbourne. Hage, G. 2003, Against Paranoid Nationalism: Searching for hope in a shrinking society, Pluto Press, Annandale, NSW.

Ho, C. 2004, Migration as feminisation [electronic resource] : Chinese women's experiences of work and family in contemporary Australia, PhD thesis, School of Economics and Political Science, Sydney, University of Sydney.

Honneth, A. 1995 [1992], Struggle for Recognition: The Moral Grammar of Social Conflicts, trans. J. Anderson. Polity Press, Cambridge.

Husband, C. and Alam,Y. 2011, Social Cohesion and Counter-terrorism: a policy contradiction? Policy Press, Bristol.

Jakubowicz, A. 1997/2010, Is Australia a racist society? : reflections on globalisation, multiculturalism and Pauline Hanson, Jakarta, Australia Indonesia Institute, and at http://andrewjakubowicz.com/publications/is-australia-an-racist-society-reflections-onglobalisation-multiculturalism-and-pauline-hanson/

Jakubowicz, A. 2009a, 'Cosmopolitanism with roots: the Jewish presence in Shanghai before the Communist Revolution and as brand in the new metropolis', in Hemelryk Donald, S., Kofman, E. and Kevin, C. (eds.) Branding Cities, Routledge, London.

Jakubowicz, A.H. 2009b 'New groups and social cohesion in australia', in Higley,J. and Nieuwenhuysen, J. with Neerup, S. (eds.) Nations of Immigrants: Australia and the USA Compared, Elgar, London.

Jakubowicz, A. 2011a, 'Empires of the Sun: towards a post-multicultural Australian politics', Cosmopolitan Civil Societies Journal, vol.3, no. 1, pp. 65-85.

Jakubowicz, A. 2011b, 'Chinese Walls: Australian multiculturalism and the necessity for human rights’, Journal of Intercultural Studies, vol.32, no. 6, pp. 693-708. 
Jakubowicz, A., Collins, J. and Chafic, W. 2011, 'Young Australian Muslims: social ecology and cultural capital', in Mansouri, F. and Marotta, V. (eds.), Muslims in the West, Melbourne University Press, Melbourne.

Koleth, E. 2010, 'Multiculturalism: a review of Australian policy statements and recent debates in Australia and overseas', Research paper No. 6 2010-2011, Parliamentary Library, Canberra. http://www.aph.gov.au/library/pubs/rp/2010-11/11rp06.pdf

Kwok, J.T. 2008, 'Clientelism in the ethnopolis: ethnic contribution networks and political fundraising under late multiculturalism', Journal of Australian Studies, vol. 32 no.4, pp. 467-479.

Kwok, J.T. 2011, 'Chinese Australian Urban Politics in the Context of Globalisation', Cosmopolitan Civil Societies Journal, vol. 3 no.1, pp. 86-102.

Leigh, A. 2010, Disconnected, UNSW Press, Kensington.

Markus, A 2011, Australia's melting pot feeling the heat, (April 5) http://www.abc.net.au/unleashed/55336.html

Pan, L. 1982/1991, In Search of Old Shanghai, Joint Publishing (H.K.), Hong Kong.

Phillips, T., and Smith, P. 2008, 'Cosmopolitan beliefs and cosmopolitan practices; An empirical investigation', Journal of Sociology, vol.44, no. 4, pp. 391-399.

Portes, A. 1998, 'Social capital: its origins and applications in modern sociology', Annual Review of Sociology, vol.24, pp. 1-24

Putnam, R. D. 1995, 'Bowling alone: America's declining social capital', Journal of Democracy, vol. 6, no.1, pp. 65-78.

http://muse.jhu.edu/demo/journal_of_democracy/v006/putnam.html

Putnam, R. D. 2007, 'E Pluribus Unum: Diversity and Community in the Twenty-first Century The 2006 Johan Skytte Prize Lecture', Scandinavian Political Studies vol. 30, no. 2, pp. 137-174

Robertson, A. 2010, Mediated Cosmopolitanism: the world of television news, Polity, Cambridge.

Roth, L. 2007, Multiculturalism, NSW Parliamentary Library Briefing Service, Briefing Paper 9/07, Sydney.

Siisiäinen, M. 2000, Two Concepts of Social Capital: Bourdieu vs. Putnam, Paper presented at ISTR Fourth International Conference "The Third Sector: For What and for Whom?" Trinity College, Dublin, Ireland July 5-8, http://www.istr.org/conferences/dublin/workingpapers/siisiainen.pdf

Wise, A. 2005, 'Hope and Belonging in a Multicultural Suburb', Journal of Intercultural Studies, vol. 26, pp. 171-186.

Woodward, I., Skrbis, Z., and Bean, C. 2008, 'Attitudes towards globalization and cosmopolitanism: cultural diversity, personal consumption and the national economy', British Journal of Sociology, vol.59, no. 2, pp. 207-226. 